\title{
Observing Subtleties: Traditional Knowledge and Optimal Water Management of Lake St. Martin
}

\author{
Myrle Traverse and Richard Baydack
}

\begin{abstract}
Lake St. Martin First Nation is an Anishinaabe community situated northwest of the Narrows at Lake St. Martin in central Manitoba. The land around Lake St. Martin and traditional activities have been affected by flooding since the early 1960's, soon after construction of the Fairford Dam on Lake Manitoba. This research explored the historical water situation at Lake St. Martin; examined the First Nations perspective on water level changes over time; and analysed water resource data for the region. Although analysis did not show with statistical significance that the flood control system and its operation are the cause of the flooding at Lake St. Martin, water level changes were evident. First Nations perspectives on the situation, however, revealed that subtle changes in the environment resulting from the operation of the water control system could be identified by traditional, common sense observation. Despite the lack of statistical significance that was due to the large variation in the data and which is characteristic of these types of large complex water systems, First Nations have known through observation of subtle changes that their environmental landscape has deteriorated as a result of the water structure.
\end{abstract}

\section{Introduction}

Lake St. Martin is located in central Manitoba, approximately 255 kilometers north of Winnipeg, between Lake Manitoba and Lake Winnipeg (Figure 1). There are three First Nation communities located downstream from the dam, Lake St. Martin, Fairford, and Little Saskatchewan. The objectives of this paper are to: 1) provide hydrologic analysis of water levels at Lake St. Martin of pre- and post-construction of the dam; 2) determine First Nations perspectives on water level changes; 3) contrast First Nation perspective at Lake St. Martin in relation to the hydrologic database; and 4) demonstrate the importance of observing subtleties in resource management.

\section{Background on Lake St. Martin}

Lake St. Martin has been repeatedly exposed to flooding since the construction of the Fairford Dam in 1961. The Portage Diversion that came into operation in 1970 has only compounded the situation. Three water bodies are situated downstream from Fairford Dam: Fairford River, Lake St. Martin, and Dauphin River. Lake St. Martin is between the two larger lakes - Lake Manitoba and Lake Winnipeg. Both Lakes Manitoba and Winnipeg are artificially controlled resulting in the excess water to be diverted into Lake St. Martin.

A study was conducted in 1956 by the Lakes Winnipeg and Manitoba Board to evaluate flood damages around Lake Manitoba. The Board recommended the construction of a new control structure at the outlet of Lake Manitoba in the Fairford River (Manitoba Water Commission 1973). The vast area of Lake Manitoba made available natural facilities for substantial storage during periods of high runoff, and in consequence, the inadequate withdrawal of these excessive amounts gave rise to high water levels during periods of abnormal runoff (Wu 1955).

\section{Correspondence}

Myrle Traverse and Richard Baydack, Natural Resources Institute, University of Manitoba, Winnipeg, Manitoba. CANADA. mtravers@mb.sympatico.ca

Ethnobotany Research \& Applications 3:051-055 (2005) 


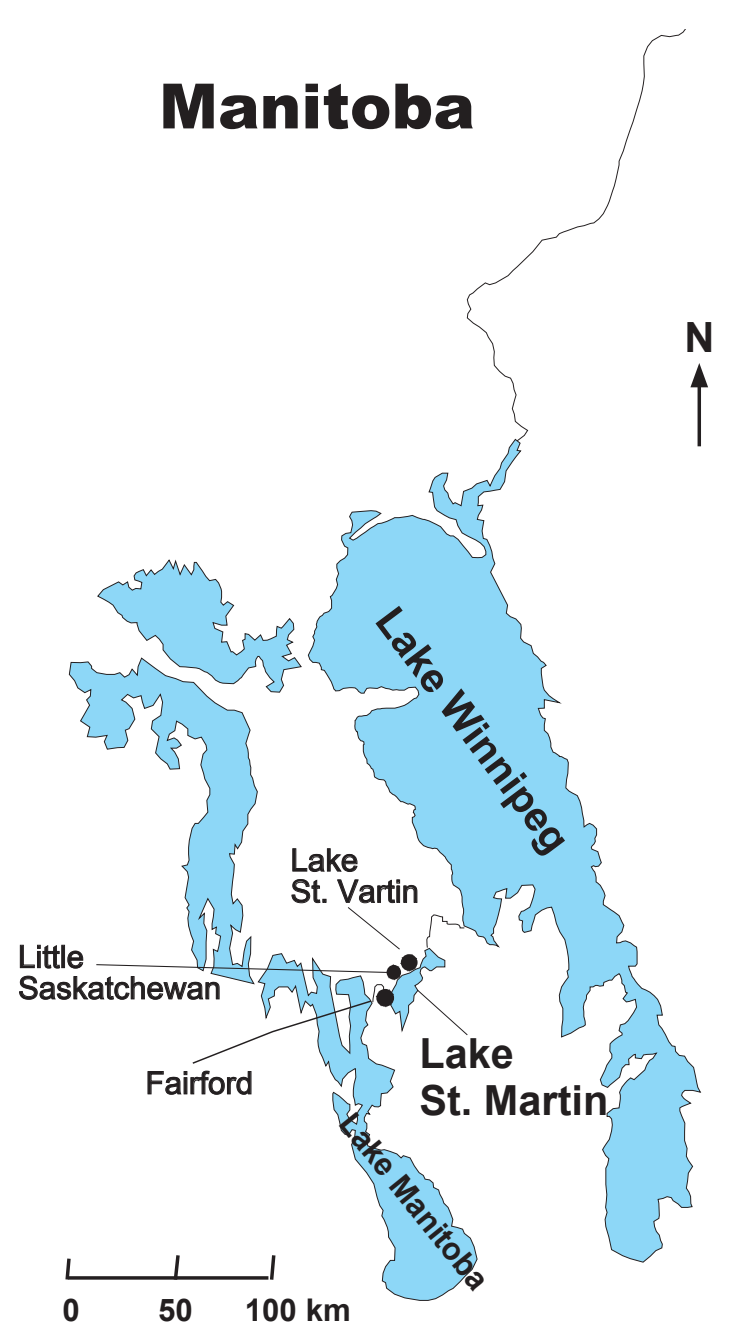

Figure 1. Lake St. Martin, Manitoba, CANADA.

The Portage Diversion was completed and has been in operation since 1970 . It is a 28.8 kilometre long channel designed to carry up to $42,482,500 \mathrm{~L} / \mathrm{m}$ (litres per minute) of flood flow from the Assiniboine River into Lake Manitoba (Galay 1964, Department of Natural Resources 1980).

Lake St. Martin is located upstream from Lake Winnipeg and they are linked by Dauphin River. A study conducted by Kuiper (1958), indicated that regulating Lake Manitoba would at times cause a slight increase in the level of Lake Winnipeg. The effect was considered so minute that it was not taken into consideration (Kuiper 1958).

\section{Hydrological Analysis and Interpretation}

Regression analysis results indicated that Lake St. Martin water levels have been affected by the construction of
Portage Diversion, and that there is a relationship between the water levels at Assiniboine River and Lake St. Martin, Lake Manitoba and Lake St. Martin, and Lake Winnipeg and Lake St. Martin (Figures 2, 3, and 4).

However the increase in water levels in each comparison are not significant according to statistical tests. The high error rate for each of the experiments indicates that the lines could be the same 95\% of the time (Traverse 1999). Figures 2, 3, and 4 show comparative regression relationships between water levels for Pre-Portage and Post-Portage Diversion conditions. The results from these experiments indicate that Portage Diversion directly affects the relationship between the water levels between Assiniboine River and Lake St. Martin, Lake Manitoba and Lake St. Martin, and Lake Winnipeg and Lake St. Martin. The results in Figures 2, 3, and 4 depict changes in the water level from a low of 0.1 metres to a high of approximately 2.5 metres.

The results indicate that there is a great deal of variation in data for this type of large-scale water system as supported by the variations in the water levels. Any actual differences are therefore concealed by the extreme variability. The degree of the changes occurring are minimal and the variation in data is very large. Tests of this nature rarely show any significant differences because of the high variations.

The results of the statistical tests strengthen the argument that Western Science relies on concrete data and bases its decisions only on these data. However, the First Nation people base their observations and knowledge on subtle changes in the environment, changes that Western Science is unable to capture, as in the case of the preceding experiments. Western Science depicts that there is no significant change in the water levels at Lake St. Martin, yet the First Nations people have been able to identify the subtle changes in their environment which are the result of the repeated water fluctuations that the results of the altered water systems (Traverse 1999).

\section{First Nation Perspective Of The Lake St. Martin Water Levels.}

The dam was initially built to maintain the water levels on the Lake Manitoba side (University of Manitoba Civil Engineering Department 1960). However, water levels are maintained on the Lake Manitoba side, but the effect is that water levels are also controlled downstream. The resulting effect is that the dam is opened, then shut, forcing the water levels to go up and down (Traverse 1999). The constant flooding from the fluctuating water levels has caused a lot of damage to the land adjacent to Lake St. Martin. The First Nation people have observed subtle changes where outsiders have not noticed the changes. 


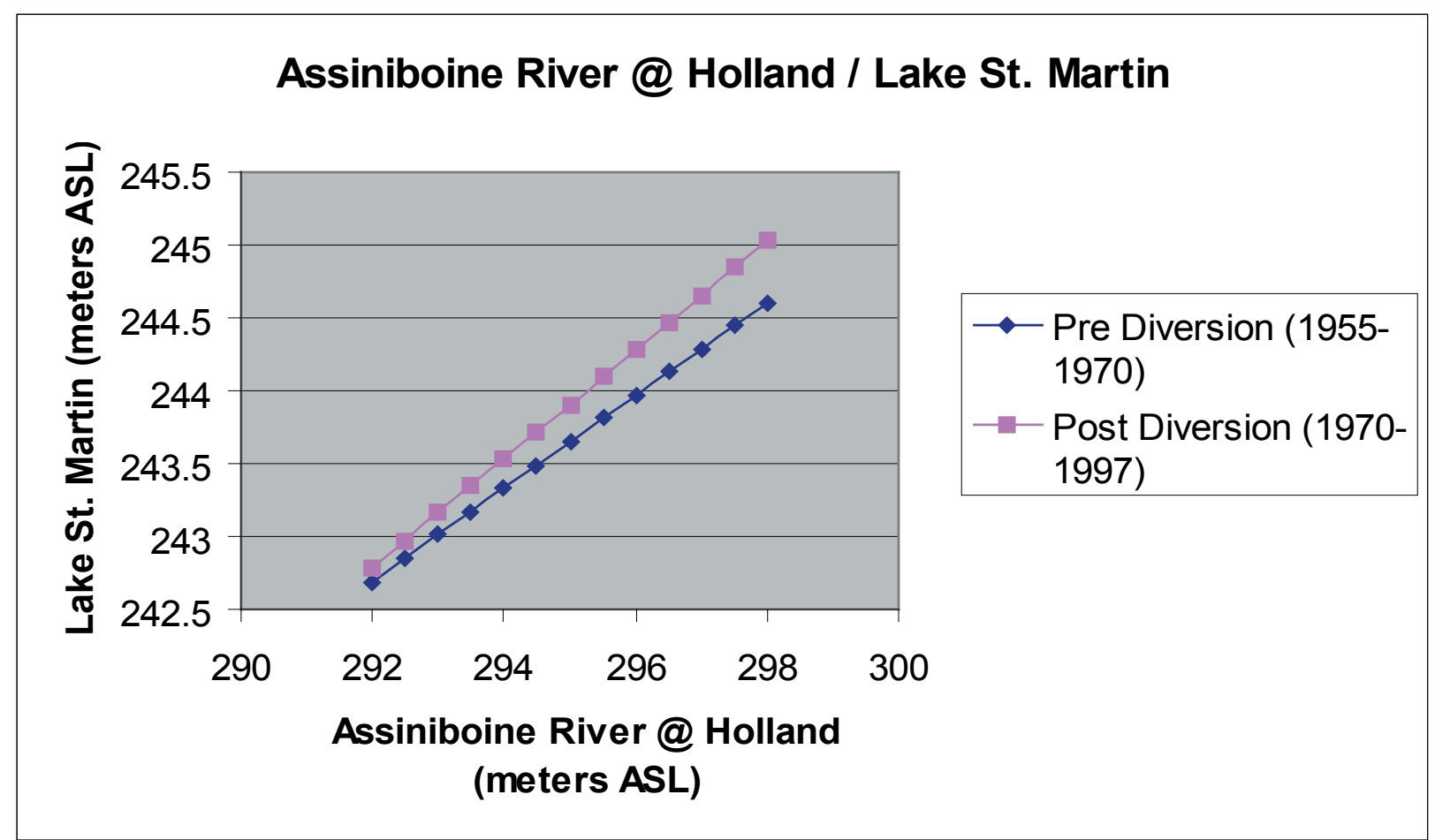

Figure 2. Water levels of Lake St. Martin and Assiniboine River depicting pre- and post- diversion.

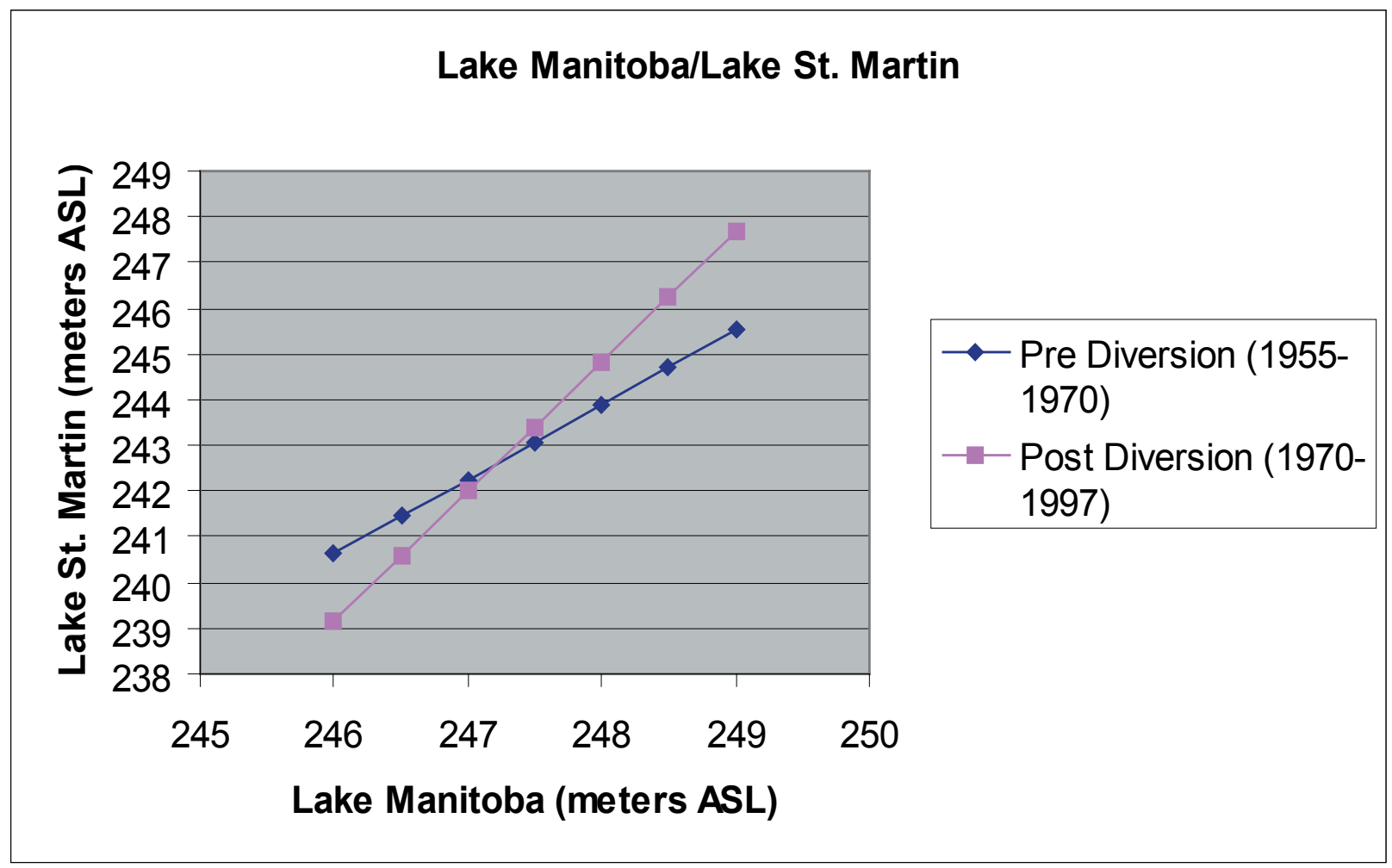

Figure 3. Water levels of Lake St. Martin and Lake Manitoba depicting pre- and post- diversion. 


\section{Lake Winnipeg / Lake St. Martin}

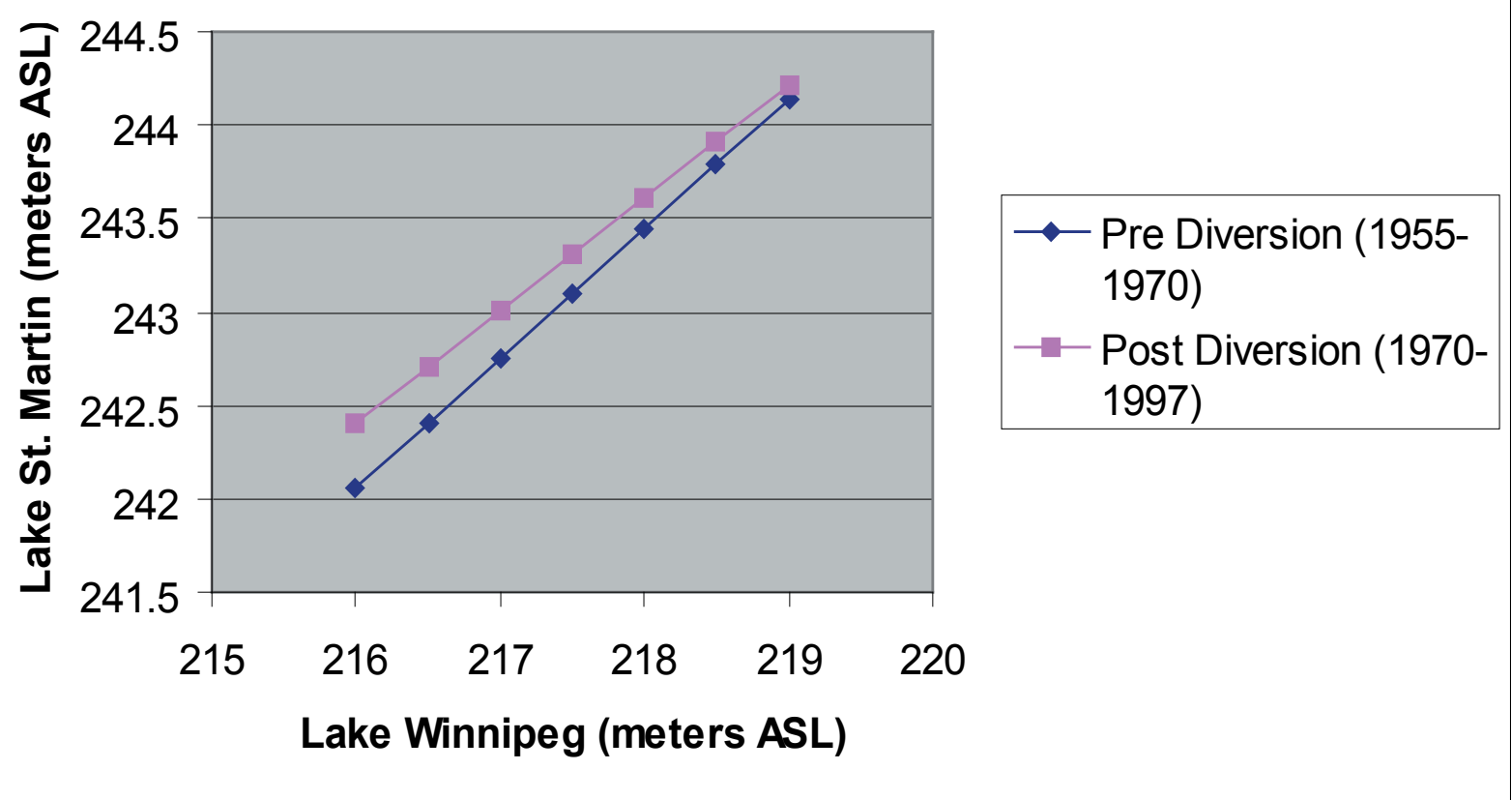

Figure 4. Water levels of Lake St. Martin and Lake Winnipeg depicting pre- and post- diversion.

Prior to construction of the dam, fishers caught more fish than they do now. The First Nations maintain that fish do not taste the same as they used to. The fish have a 'grassy taste' to them, and the First Nations people believe that this is due to their habitat which has become grassy as a result of the flooding (Traverse 1999).

Hunting has been severely curtailed as a result of the altered water regime. The First Nations have expressed their concerns over the decline and different taste in wildlife species that once thrived around Lake St. Martin First Nation. The First Nations have also noticed that wildlife such as deer, moose, rabbit, and grouse do not taste as good as they once did. First Nations used to hear birds singing all over the area, now a song is seldom heard (Traverse 1999).

The First Nations used to gather various species of edible berries every summer. Species that grew along the shoreline such as gooseberries have been decimated. Medicinal plants that grow in the flooded area are directly affected. For example, wikhe (sweet flag or Acorus calamus L.), which is chewed for sore throats and to prevent colds, is found along riverbanks. However, the plant cannot grow if water levels are too high (Traverse 1999).

Much of the land southwest of the Narrows used to be prime hay land, now most of it is under water. Fields, in which hay once thrived, are now home to bulrushes, reeds, and swamp (Traverse 1999). The vegetation and landscape around Lake St. Martin is visibly affected by the higher water levels, most notable is the lack of trees around some areas along the Lake St. Martin First Nation shoreline. The First Nations remember when they used to go to the shore in the 1950's to do their laundry in the lake, and how they used to sit in the shade under the trees, however, the trees have since disappeared. Prior to the flood, the First Nations used to walk to the shore from their houses, but much of the area is now swamplike, muddy, and has been replaced by reeds. Most of the shoreline is permanently wet and foul smelling and spans approximately one kilometre inland in some places (Traverse 1999).

\section{Understanding the Subtleties of Traditional Knowledge Systems}

The subtleties of traditional knowledge systems refer to the five senses in which First Nations are attuned in observing their environment. Subtleties refers to the senses of smell, hearing, touch, and taste in which the First Nations use to observe and interact with their environment. The traditional knowledge systems of the First Nations offer a view of the world, of past, present, and future, and base observations in relation to past and present phenomena. They are different from those of the white man whose knowledge is based solely on explaining and rationalizing 
events (Traverse 1999). Traditional knowledge systems consist of the observations of nature by elders and other First Nations, through an awareness of the subtle and obvious changes in nature (Traverse 1998).

The changes identified by the First Nations are subtle, but these subtleties verify and support the subtleties identified by hydrologic changes, which have been revealed by the various analyses. First Nations approaches to observations are therefore able to detect these minor changes which western science could not. Even though the revelations in the analyses may be minute and not considered statistically significant, they do support what the First Nations people have known and identified all along - that the alteration in the water levels has been the result of the Portage Diversion and Fairford Dam (Traverse 1999).

The difference between traditional and western knowledge systems are obvious in that First Nations have affirmed that the Earth should be respected and not altered. The alteration of the water levels has been detrimental for the First Nations. First Nations have noticed subtle changes in their environment; however, westerners need to verify the changes only if they are obvious and visible. First Nations observe the changes through abstract thoughts, and mental and qualitative tracking of events. Westerners rely on concrete, quantitative and physical recording of information. First Nations believe that they should share their resources, however, westerners have a cost/benefit rationale attached to sharing.

\section{Conclusion}

This paper has emphasized the importance of observing subtleties. Subtleties are part of micro aspects of traditional knowledge systems among the First Nations people. Its importance challenges the macro aspect of western knowledge systems. Results from the hydrological analyses did not support what the First Nations knew all along, that the Fairford Dam is contributing to the flooding. This indicates that the subtle changes, which came about from the construction of the Fairford Dam, could not be detected by statistically based analyses, even though they were obvious to First Nations residents. This suggests that First Nations knowledge bases should be more fully considered in environmental decision-making. A thorough analysis of First Nations perceptions has thus become necessary for optimal management of natural resources into the Millennium.

\section{Literature Cited}

Galay, V. 1964. Portage Diversion: Hydraulic Model Studies of Drop Structure No. 1. Province of Manitoba: Department of Agriculture and Conservation - Water Control and Conservation Branch.
Kuiper, E. 1958. Benefit-Cost Analysis: Lake Manitoba Regulation. University of Manitoba, Winnipeg.

Manitoba Water Commission. 1973. Lake Manitoba Regulation. Volume 1. Province of Manitoba, Winnipeg.

Traverse, M. 1998). Blending Traditional Environmental Knowledge with Western Science: An Approach to Sustaining First Nation Communities. Unpublished.

Traverse, M. 1999. Analyzing the Effects of the Fairford Dam at Lake St. Martin First Nation. M.Sc. Thesis, University of Manitoba, Winnipeg.

University of Manitoba Civil Engineering Department. 1960. Report No. 1: Fairford River Channel Improvements. Manitoba, Winnipeg.

Wu, K. 1955. Investigation of Means of Lowering Lake Manitoba Levels: Upper Fairford River Channel Improvement Studies. Province of Manitoba, Winnipeg. 
